\title{
Treatment Completion in a Cognitive Behaviour Therapy Service for Problem Gamblers: Clinical Outcome Study
}

\author{
Barry Tolchard ${ }^{1 *}$ and Malcolm Battersby ${ }^{2}$ \\ Health University of New England, University of New England, Armidale, NSW, Australia
}

\begin{abstract}
Increased access to gambling is proving to be a great burden on the individuals who partake, their families and society in general. Despite growing evidence for the use of Cognitive-Behaviour Therapy (CBT) with problem gamblers, important questions remain unanswered regarding those individuals who do not respond to CBT. This paper compares gamblers who are considered 1) treatment completers, 2) drop-out following an initial assessment and, 3) drop-out after commencing treatment from a specialized CBT service. The results indicate a number of differences between the groups in regard to gambling severity and behaviour, demographic profile and variations in overall psychopathology.
\end{abstract}

\section{Keywords: Problem gambling; Treatment; Outcomes}

\section{Introduction}

The world-wide proliferation of opportunities to gamble is generating increasing numbers of people whose gambling results in serious social and personal harm [1]. Problem gambling is now recognised as a mental health issue requiring the attention of specialist treatment services $[2,3]$. A number of treatment strategies have been developed ranging from traditional medical approaches such as medication management and 12-step programs to talking therapies based on psychodynamic and Cognitive-Behaviour Therapy (CBT) models [4-6]. CBT is emerging as the most successful nonpharmacological treatment for gambling disorders [7-12].

\section{Treatment failure in problem gamblers}

In problem gambling research, very little has been reported on treatment non-responders. Melville, Casey and Kavanagh have a systematic review of the gambling literature regarding drop-outs [13]. They summarize the results of 12 published works where drop-out is described and the characteristics of those who drop-out compared with treatment completers. From their review, they note that drop-out ranges from 14 to 50 per cent in samples. This gave a median drop-out of $26 \%$ which increased to $31 \%$ when calculated as a weighted average. Of these 12 studies, 10 used CBT, with two studies based on self-help and Gamblers Anonymous (GA). In CBT the drop-out rate ranged between $14-50 \%$, with a median of $38 \%$ and weighted average of $32 \%$. The reported drop-out from the other two studies was $22 \%$ [13].

A common problem when reporting non-response rates as highlighted by Melville et al. is that different criteria are used to define such an event. For example, Ladouceur and colleagues considered a treatment completer to be someone who attended at least three sessions $[9,13,14]$. These same criteria would be considered a drop-out according to Robson, Edwards, Smith, and Colman [15].

\section{Specific gambler characteristics related to treatment success}

According to Melville et al. a number of risk factors have been identified among the studies that have included drop-out data, although much of this evidence is not always consistent across different studies [13]. One study indicated that social support was related to treatment non-completion of gamblers with the inclusion of significant others into treatment for better outcomes [16,17]. A number of studies identified gamblers who were unemployed being at risk of drop-out $[18,19]$.

There is emerging evidence of a relationship between specific gambling behaviour and risk of drop-out. Significantly higher levels of gambling severity prior to entering treatment is implicated in increased non-completion, suggesting a need for greater emphasis on the relapse prevention component of treatment [20]. Those who gamble at an earlier age and gamble for longer are more likely to drop-out of treatment [13]. There is evidence relating drop-out to other factors such as co-morbid psychopathology, including depression and anxiety $[8,18,21]$.

Gambling specific and individual characteristics have been noted in several studies. Grant, Kim, and Kuskowski on performing a retrospective analysis of treatment non-responders, concluded that drop-out in treatment clients did so due to the 'loss of the thrill' to gambling and because they continued to believe they could still win and so alleviate their financial problems [22]. Leblond et al. noted that high scores on impulsivity at intake significantly differentiated those participants who dropped out from treatment completers (p. 207) [21]. Similarly, Smith, Harvey, Battersby, Oakes \& Baigent report elevated sensation seeking to be a predictor of dropouts. Dunn et al. noted treatment specific factors including non-compliance with homework tasks and a lack of readiness for change indicated greater risk of dropout $[23,24]$. The importance of the therapeutic relationship has been suggested to be important in achieving positive treatment outcomes [25]. In another study the CBT model used was reported to influence treatment completion. Jimenez-Murcia et al. found that exposure with response prevention was more likely to lead to drop out than standard CBT based on cognitive restructuring [26]. However, they also noted that those completing treatment showed no differences in outcome related to the therapeutic stance.

This paper examines the treatment of problem gamblers using CBT and addresses the reasons why individuals may or may not complete treatment using this approach. The overall aims were to identify typical

*Corresponding author: Barry Tolchar, Deputy Head of School Research Health University of New England, Australia, Tel: +62435781040; E-mail: btolchar@une.edu.au

Received August 26, 2013; Accepted October 29, 2013; Published December 06, 2013

Citation: Tolchard B, Battersby M (2013) Treatment Completion in a Cognitive Behaviour Therapy Service for Problem Gamblers: Clinical Outcome Study. J Addict Res Ther 4: 165. doi: 10.4172/2155-6105.1000165

Copyright: (c) 2013 Tolchard B, et al. This is an open-access article distributed under the terms of the Creative Commons Attribution License, which permits unrestricted use, distribution, and reproduction in any medium, provided the original author and source are credited. 
characteristics of those being referred for treatment, the nature of their gambling problem and differences between completers and noncompleters. The relationship between underlying psychopathology and the impact this has in terms of treatment completion will be examined. The primary aim of this study was to examine factors that contribute to treatment completion and drop-out. A secondary aim was to consider better targeted treatment/interventions that take into account the individual differences and so reduce the overall risk of drop-out.

\section{Design and Method}

\section{Subjects}

This study is a clinical outcomes study of problem gamblers referred to a specialist treatment service. The study reports on 205 clients recruited from an out-patient program seen individually for CBT. Each client was offered treatment as per the services protocol, which is described. All clients were offered abstinence or controlled gambling as a treatment outcome. Consent was sought from all clients in the study and treatment was not affected if a client preferred not to have their data included.

\section{Setting and therapists}

The program was based in a specialist gambling service in a large teaching hospital in Adelaide, Australia. The service provides both out and in-patient programs and offers individual, group and self-help treatments. The service is funded by local government using money from the gambling industry to sponsor a range of gambling treatment services. Clients are drawn from a geographical area covering all of South Australia and parts of Victoria, New South Wales and the Northern Territory ( $>1,000000$ sq. kms 3 times the size of Great Britain or equivalent to New Mexico and Texas combined). All therapists were trained to master's level in CBT and drawn from a range of professionals including nursing, psychiatry, social work and psychology. All therapists' receive weekly clinical supervision from $\mathrm{Ph}$.D. trained supervisors.

\section{Assessment}

Therapists conducted a validated semi-structured assessment based on CBT principles [27]. Assessment determines the current nature of the presenting problem as well as the impact and course of the problem. Following assessment, clients are deemed suitable or not and offered treatment or an alternative. Suitability is based on a number of factors including motivation, agreement on common goals for therapy, severity of depression, suicidality or florid psychosis. As the service is part of a larger CBT program, clients may be treated separately for these problems by the same therapists and then enter gambling treatment once there is a reduction of symptomatology. Alternatives to treatment include referral to financial counselling, medication through their general practitioner or specialist treatment for their other psychopathologies.

\section{Measures}

In addition clients completed the following;

Victorian Gambling Screen (VGS): This is a 21-item measure of gambling with three sub-scales, of which the 15-item Harm-Self Scale (H-SS) is used to determine problem gambling rates. The $\mathrm{H}-\mathrm{SS}$ has a total score of 60 with a score of $14+$ indicating pathological and $21+$ problem gambling [27-29]. This measure has been found to be reliable with a Chronbach's alpha of .96. This has been confirmed in other populations including a specific clinical group adolescent and in a general survey [28-31].

South Oaks Gambling Screen (SOGS): This is a 20-item self-report questionnaire providing a cut-off score for pathological gambling using DSM III-R criteria. The accepted cut-off for problem gambling is five $[32,33]$. This measure has been used widely in a range of areas including prevalence surveys, clinical and specific population studies [34].

Beck Depression Inventory (BDI): This commonly used selfreport questionnaire provides severity cut-offs for depression into mild, moderate and severe, and is a validated and reliable measure of change over time [35].

Beck Anxiety Inventory (BAI): Similar to the BDI this self-report questionnaire provides severity cut-offs for anxiety into mild, moderate and severe and is a validated and reliable measure of change over time [36].

Main problem/Goals: This is an individualised visual analogue scale ranging from 0 -no problem to 8 -most severe problem and is a statement of the person's main problem, described by them in behavioural terms, providing a client-centred measure of change over time [37]. This measure has been used across a number of settings and been found to be a meaningful measure of improvement [38,39].

Work and Social Adjustment Scale (WSAS): This generic self-report measure of disability and handicap covers five areas of functioning on a $0-40$ scale. It has a good internal consistency with a Chronbach's $\alpha$ between 0.7 to $0.9[37,40]$. This scale has been proven valid across a number of populations [41,42].

BreakEven Network Questionnaire (BEN-Q): A combined score taken from four Likert scales (0-8) measuring gambling urge, state of financial problems, overall gambling severity and management of finances used by all Break Even services in South Australia [43]. This measure has not been fully validated although in one study it was shown to be reliable (Cronbach's $\alpha=.819$ ) [28].

All measures were repeated at pre- and post-treatment and 1-, 3-, 6-, and 12-month follow-up.

\section{Treatment}

After initial screening, clients were either seen individually, admitted to the in-patient program or are referred to the next treatment group. Admission to the in-patient program is determined by a number of factors including active suicidal behaviour, limited social support severe psychomotor retardation. The main model of treatment involves exposure with adjunct cognitive strategies and has been described elsewhere $[7,11,12,44]$. A clear rationale for treatment is offered to all clients and an individual formulation prepared. All clients in this study were from the out-patient program.

In summary; sessions 1-2: assessment, baseline measurement, setting goals of therapy and formulation, sessions 3-6: establishing an individual program to work on goals of therapy, consider stimulus control issues, identify first homework task based on the exposure model and ensure structures are in place for the client to achieve tasks, sessions 7-8: introduce cognitive components where required, work on relapse issues and prepare for discharge, sessions 9-10: discharge, carry out repeat measures and plan relapse strategies and, follow-up sessions at $1,3,6,12$ and 24 months post-completion.

\section{Data analyses}

Wherever possible, compares the following three groups. Completers (C) and non-completers (drop-out at assessment-DO-A and drop-out in treatment-DO-T). A person was considered to be a DO-A if they only attended the assessment sessions but had no formal 
treatment and a DO-T had attended at least one treatment session. However, as this was a clinical outcome study no specific power calculation was carried out. All groups were compared using standard statistical methods. All data was analysed by the main author with categorical variables using chi square and continuous variables using t-tests, correlations and ANOVAs.

\section{Results}

\section{Demographic data-all gamblers}

These data are based on 205 clients who had completed treatment, dropped-out at assessment or dropped-out during treatment (Table 1). Female gamblers significantly outnumbered males $\left(\chi^{2}(1, N=205)\right.$ $=5.31 ; p<.05)$ ). Overall, gamblers in this study had higher rates of divorce (34\%), lived alone (37\%) and were on lower annual incomes (72.6\%) compared to the Australian average. The unemployment rate of the sample was several times higher than the national average [45].

Referrals were from two main sources, primary gambling services (32\%) or General Practice (50\%) with the remainder from industry, community mental health agencies and other sources. There were no significant demographic or gambling severity differences within the cohort based on referral source. The last South Australian gambling report suggested that clients from the treatment program being described here did not differ greatly from clients of other local gambling treatment services on most measures [46]. The exceptions to this were that clients from this service generally earned less in salaries and wages compared with those referred from other services $(<\$ 500 /$

\begin{tabular}{|c|c|c|}
\hline & $\mathrm{n}$ & $\%$ \\
\hline \multicolumn{3}{|l|}{ Gender } \\
\hline Male & 86 & (42.0) \\
\hline Female $^{*}$ & 119 & $(58.0)$ \\
\hline \multicolumn{3}{|c|}{ Current Relationship status } \\
\hline Never Married & 42 & (27.3) \\
\hline Married & 54 & (35.1) \\
\hline Separated & 52 & (33.8) \\
\hline Widowed & 6 & (3.9) \\
\hline Other & 0 & $(.0)$ \\
\hline \multicolumn{3}{|l|}{ Living Arrangements } \\
\hline Living Alone & 56 & (37.3) \\
\hline Couple & 54 & $(36.0)$ \\
\hline Single Parent Family & 12 & $(8.0)$ \\
\hline Living with Parents & 20 & (13.3) \\
\hline Other & 8 & $(5.3)$ \\
\hline \multicolumn{3}{|l|}{ Gross Income } \\
\hline$<\$ 500$ & 90 & $(72.6)$ \\
\hline$\$ 501-\$ 1000$ & 30 & $(24.2)$ \\
\hline$>\$ 1000$ & 4 & (3.2) \\
\hline \multicolumn{3}{|l|}{ Employment } \\
\hline Employed & 96 & $(49.5)$ \\
\hline Unemployed & 34 & (17.5) \\
\hline Home duties & 32 & (16.5) \\
\hline Student & 8 & $(4.1)$ \\
\hline Retired & 22 & (11.3) \\
\hline Other & 2 & $(1.0)$ \\
\hline
\end{tabular}

Note. \# Numbers vary due to missing data; 29 clients were still in treatment and are not included in the analysis; ${ }^{*} p<.05$

Table 1: Demographic data for all gamblers ${ }^{\#}$ week; $72.6 \%$ vs. $44.5 \%)$. They had also been experiencing their problem for longer ( $>5$ years; $53.9 \%$ vs. $31.1 \%$ ) and spent a greater amount of time gambling (> 50 hours per week; $23.9 \%$ vs. $11.2 \%$ ) [46].

\section{Completers versus non-completers}

Non-completers were; DO-A 44 (21.5\%) and DO-T 18 (9\%), which yielded an overall completion rate of $143(69.8 \%)$. This level of noncompletion is similar to the rates observed in a previous descriptive evaluation for the same service $[12,44]$; although there was an overall reduction in the total DO-T levels from $17 \%$ down to $9 \%$ from the previous report.

When comparing completers with non-completers a number of differences emerged. Clients dropping out during the treatment phase (DO-T) were more likely to be male $\left(\chi^{2}(1, N=205)=5.31, p<.05\right)$. There was a trend towards male DO-Ts exhibiting higher anxiety (BAI) scores than men in the other groups ( $M=25$ vs. 15 (Cs) \& 16 (DO-A)). This difference in anxiety scores was not found in DO-A or completers. Although there were no differences in gender in the DO-A group, it was noted that the female gamblers from this group also exhibited higher levels of anxiety that were similar to that of the males in the DO-T group ( $F=22.9$ vs. $M=24.3$, mean scores on the BAI). This level of anxiety was similar to that of females in the completers (18.8). In terms of follow-up, it was noted that more females continued to attend sessions post-treatment beyond the 12 month period $\left(\chi^{2}(1, N=205.00)\right.$ $=119.00, p<.001)$.

Age differences emerged, with younger gamblers tending to dropout prior to starting treatment, $\chi^{2}(4, N=205)=30.70, p<.001$. In relation to age it was found that while there were little differences in terms of gambling severity using the SOGS; VGS scores were higher in the younger gamblers. No age-related differences were observed for any other measures.

With regard to marital status the majority of those who dropped out during assessment had never married $\left(\chi^{2}(5, N=205)=35.73, p<\right.$ $.001)$ and this effect did not appear to be confounded by age in that the range of drop-outs was evenly spread across the age groups. There were no significant differences between the groups on employment status and gross personal income, although DO-T's were more likely to be employed in a low wage job.

\section{Gambling behaviours and severity}

The BEN-Q asks gamblers for a range of self-reported behavioural responses related to gambling. The majority $(90 \%)$ played Electronic Gaming Machines (EGM or slots) and on average played for 33 hours per week, spending $\$ 500-\$ 1000$ per week. With an average weekly income of $<\$ 500$ it is clear that gamblers presenting to the service were spending more than they earned. Most gamblers had been experiencing a problem for over 5 years (54\%) with almost all playing more than once per week (85\%), and spending more than they intended on each visit (87\%).

There were a number of differences in gambling behaviours between the three groups. All non-completer groups were EGM players. This is not surprising since $90 \%$ of all gamblers played EGMs. All gamblers in the DO-T group and $71.4 \%$ in the DO-A group had been involved in the activity for longer than 5 years compared with $45 \%$ of the completers. The DO-T and DO-A groups were also regular gamblers and played 'daily or more often' (60\% \& 57.1\%) compared with completers $(27.5 \%)$. There was no difference in the total amount of money gambled on each visit between the groups or the amount of time spent gambling (Table 1). 
All gamblers within the three groups scored above the acceptable cut-off for problem gambling on SOGS and VGS. There were no differences in overall severity between the groups on either of these measures. The clients scored high in terms of gambling impact as measured by the relevant questions from the BEN-Q. These are four questions rated from 0-no impact to 8-maximum impact (Table 2). There was a significant difference in one of the items where reported levels of urge to gamble was lower in the DO-T group, $F(2,204)=3.98$, $p<.05$. There were no differences on the remaining three items with high gambling severity scores for all gamblers presenting to the service.

\section{Psychiatric pathology}

No differences were observed in psychiatric pathology measured. Depression was measured by the Beck Depression Inventory (BDI). Scores were generally in the moderate to severe range with an average rating of 22 at assessment for all gamblers. Between group comparison revealed few differences for depression with DO-A clients having an overall higher level of pathology $(F(2,169)=1.10, p>.05)$. There were a number of differences in levels of anxiety with most gamblers falling in the high range of the Beck Anxiety Inventory (BAI) with a mean score of 18.2. When comparing completers versus the non-completers there was a trend for completers to be less severe $(F(2,161)<1, N S)$.

There was a strong relationship with both the BDI and BAI when applying each tools accepted cut-off scores for all groups. There was a stronger relationship in the DO-A group $(r=.75)$ and less so in the DO-T $(r=.53)$ and completers $(r=.53)$ (Table 3$)$.

\section{Disability}

There were no differences on overall level of mean reported disability between groups. However, when comparing the individual items on the WSA, some differences did emerge. The DO-T group reported greater

\begin{tabular}{|c|c|c|c|c|c|c|}
\hline & \multicolumn{6}{|c|}{ Treatment Status } \\
\hline & \multicolumn{2}{|c|}{ DO-A } & \multicolumn{2}{|c|}{ DO-T } & \multicolumn{2}{|c|}{ Completed } \\
\hline & \multicolumn{6}{|c|}{$n(\%)$} \\
\hline \multicolumn{7}{|c|}{ Main Form of Gambling } \\
\hline Gaming Machines & 44 & $(100.0)$ & 16 & (89.0) & 126 & $(88.0)$ \\
\hline TAB/Racing Codes & 0 & $(0.0)$ & 0 & $(0.0)$ & 8 & $(6.0)$ \\
\hline Casino Games & 0 & $(0.0)$ & 0 & $(0.0)$ & 7 & $(5.0)$ \\
\hline Other & 0 & $(0.0)$ & 2 & (11.0) & 1 & $(1.0)$ \\
\hline \multicolumn{7}{|c|}{ Frequency spent more than could afford } \\
\hline Often & 6 & $(14.0)$ & 7 & $(40.0)$ & 16 & (11.0) \\
\hline Always & 38 & $(86.0)$ & 11 & $(60.0)$ & 127 & $(89.0)$ \\
\hline \multicolumn{7}{|c|}{ Money spent on gambling in a month } \\
\hline$<\$ 500$ & 19 & $(43.0)$ & 11 & (60.0) & 47 & (33.0) \\
\hline$\$ 501-\$ 1000$ & 13 & $(29.0)$ & 0 & $(0.0)$ & 52 & $(36.0)$ \\
\hline$>\$ 1000$ & 13 & $(29.0)$ & 7 & $(40.0)$ & 44 & (31.0) \\
\hline \multicolumn{7}{|c|}{ How often gambled in past month } \\
\hline Never & 0 & $(0.0)$ & 0 & $(0.0)$ & 0 & $(0.0)$ \\
\hline A few times & 6 & $(14.0)$ & 0 & $(0.0)$ & 0 & $(0.0)$ \\
\hline Weekly & 0 & $(0.0)$ & 0 & $(0.0)$ & 26 & (18.0) \\
\hline A few times a week & 13 & $(29.0)$ & 7 & $(40)$ & 79 & $(55.0)$ \\
\hline Daily or more often & 25 & $(57.0)$ & 11 & (60) & 40 & $(28.0)$ \\
\hline \multicolumn{7}{|c|}{ How long gambling causing a problem } \\
\hline$<12$ months & 6 & $(14.0)$ & 0 & $(0.0)$ & 7 & $(5.0)$ \\
\hline $1-5$ years & 6 & $(14.0)$ & 0 & $(0.0)$ & 72 & $(50.0)$ \\
\hline $5-10$ years & 25 & $(57.0)$ & 7 & $(40.0)$ & 54 & $(38.0)$ \\
\hline$>10$ years & 6 & $(14.0)$ & 11 & $(60.0)$ & 11 & (8.0) \\
\hline
\end{tabular}

Table 2: Relationship between Gambling behaviours and completion rate.

\begin{tabular}{|c|c|c|c|c|c|c|}
\hline & \multicolumn{7}{|c|}{ Treatment Status } \\
\hline & \multicolumn{2}{|c|}{ DO-A } & \multicolumn{2}{|c|}{ DO-T } & \multicolumn{2}{c|}{ Comp. } \\
\hline & $M$ & $(S D)$ & $M$ & $(S D)$ & $M$ & $(S D)$ \\
\hline Urge to gamble at present & 6.7 & $(1.8)$ & 4.6 & $(3.0)^{* *}$ & 6.6 & $(2.0)$ \\
\hline Financial problem due to gambling & 5.7 & $(3.7)$ & 5.6 & $(2.2)$ & 6.3 & $(2.1)$ \\
\hline State of gambling problem & 6.8 & $(1.6)$ & 6.6 & $(1.7)$ & 6.4 & $(2.1)$ \\
\hline Satisfaction with managing finances & 6.3 & $(2.3)$ & 6.6 & $(1.7)$ & 6.6 & $(1.9)$ \\
\hline ** one-way ANOVA $F(2,204)=3.98, p<.05$ & & & & & \\
\hline
\end{tabular}

Table 3: $M(S D)$ for gambling severity measured by the gambling items on the BEN-Q.

\begin{tabular}{|c|c|c|c|}
\hline & \multicolumn{3}{|c|}{ Treatment Status } \\
\hline & DO-A & DO-T & $\mathrm{C}$ \\
\hline \multicolumn{4}{|l|}{ Impact of gambling } \\
\hline Urge to gamble at present & $\uparrow$ & $\downarrow$ & $\uparrow$ \\
\hline Financial problem due to gambling & $\downarrow$ & $\downarrow$ & $\uparrow$ \\
\hline State of gambling problem & $\uparrow$ & $\uparrow$ & $\downarrow$ \\
\hline Satisfaction with managing finances & $\downarrow$ & $\uparrow$ & $\uparrow$ \\
\hline Main Problem & $\downarrow$ & $\downarrow$ & $\uparrow$ \\
\hline How long gambling causing a problem for the client & $\uparrow$ & $\uparrow$ & $\downarrow$ \\
\hline \multicolumn{4}{|l|}{ Gambling behaviour } \\
\hline How frequently spent more than could afford & & $\uparrow$ & $\uparrow$ \\
\hline How much money spent on gambling in a month & $\downarrow$ & $\downarrow$ & $\uparrow$ \\
\hline How often gambled in past month & $\downarrow$ & $\downarrow$ & $\uparrow$ \\
\hline How often gambled in past month & & $\uparrow$ & $\downarrow$ \\
\hline \multicolumn{4}{|l|}{ Gambling severity } \\
\hline SOGS & $\downarrow$ & $\uparrow$ & $\uparrow$ \\
\hline VGS & $\uparrow$ & $\uparrow$ & $\downarrow$ \\
\hline \multicolumn{4}{|l|}{ Psychopathology } \\
\hline BAl & $\uparrow$ & $\uparrow$ & $\downarrow$ \\
\hline BDI & & $\downarrow$ & $\downarrow$ \\
\hline \multicolumn{4}{|l|}{ Disability } \\
\hline WSA - Work & $\uparrow$ & $\uparrow$ & $\downarrow$ \\
\hline WSA - Home Management & $\downarrow$ & $\downarrow$ & $\uparrow$ \\
\hline WSA - Social Leisure & $\downarrow$ & $\uparrow$ & $\uparrow$ \\
\hline WSA - Private Leisure & $\uparrow$ & $\uparrow$ & $\downarrow$ \\
\hline WSA - Family and Relationships & $\downarrow$ & $\uparrow$ & $\downarrow$ \\
\hline WSA - Total & $\downarrow$ & $\downarrow$ & $\uparrow$ \\
\hline
\end{tabular}

Note: $(Z) \uparrow=p<.05 ; \downarrow=P>.05$

Table 4: Summary of the differences between completers and non-completers on gambling, psychopathological and disability measures

disability in relation to their social $\left(\chi^{2}(8, N=205)=25.01, p<.05\right)$ and private leisure time $\left(\chi^{2}(8, N=205)=19.10, p<.05\right)$ and also in their relationships with significant others $\left(\chi^{2}(7, N=205)=21.10, p<.05\right)$.

Completers presented with higher gambling scores on the gambling severity, impact measures and overall level of disability than the non-completers, although this was not a consistent finding and appears to relate mostly to their home management and social leisure time. However, despite this, their overall degree of psychopathology measured on the BAI/BDI was lower. Both non-completer groups present with similar issues, in that they had lower gambling severity and impact scores with the DO-As having corresponding lower levels of disability. However, on individual disability items, both non-completer groups appear to experience difficulties with their work and private leisure related to their gambling. While the DO-Ts report overall lower disability, their individual WSA scores fell into the higher category. Both non-completer groups report high anxiety. The DO-T group on the other hand display lower levels of depression with DO-As having 
higher depression scores. It should be noted the DO-T group contains small numbers and so the results may not accurately represent this group (Table 4).

\section{Discussion}

The findings presented in this study indicate differences in characteristics of non-completers compared with completers. Many of the findings confirm results from other individual studies and add support for certain characteristics being implicated in possible higher drop-out rates $[13,47]$. In this study, completers were typically middle aged, had recently developed their gambling problem, had spent less time on the activity compared with non-completers, and presented with lower severity levels of anxiety which is consistent with findings from other studies [24].

\section{Socio-demographic findings}

Drop-outs from assessment were likely to be single and working but in a low income jobs, experienced their problem for longer than completers, were more frequent players and had higher levels of both anxiety and depression. Drop-outs from treatment were male, employed, and experienced their problem for longer with higher frequency play, a finding noted in another study [19]. They reported higher gambling scores but due to other factors such as play frequency and response to disability issues, no longer experienced the same kind of urge to gamble as completers and DO-As. Smith et al. have suggested that while urge may decrease the gambler continues to have higher levels of sensation seeking and that this is a potential predictor of drop-out [23].

The findings show that gender may play a role in treatment completion. Male gamblers dropped-out during treatment at a higher rate than women, whereas gender was equally represented in the DO-A group. This suggests that, once female gamblers have been engaged in the treatment process, they are much more likely to continue and complete the treatment as well as attend post-treatment follow-up sessions. Elevated levels of anxiety in the female sample may give rise to a greater desire for treatment and support, above and beyond the gambling problem. If so, treatment may be more effective when combined with standard anxiety management procedures including mindfulness, enhanced coping strategies and problem solving. This flexibility of approach is a fundamental aspect of the model of treatment used in CBT which relies on individualised formulations for each client [48].

The study suggests younger gamblers are more likely to dropout prior to the commencement of treatment than others in the sample which is consistent with other studies [49,50]. Youth gamblers responded differently on the two gambling measures and it appears the VGS is more sensitive to variations in problem gambling severity than the SOGS in this population of gamblers. It is possible that the service described here, which is essentially an adult treatment program, is not well suited to this age group. Similarly, the fact that treatment works less well with those who have never married may indicate that there is a need for greater social support for single gamblers to assist them during the treatment program [20]. This is borne out by the fact that the majority were either living alone or in non-family households (67\%). A possible solution to this may be to offer group treatment or to have some extra support added to the main treatment. Examples of this might include the provision of additional support through telephone calls or e-mails between sessions to improve treatment compliance [51]. Another alternative may be to decrease the gap between sessions with perhaps 2-3 sessions per week in the first few weeks. This may help to improve engagement and improve drop-out rates with this group.

\section{Findings related to gambling behaviour}

A number of differences in gambling correlates were also observed. Overall, gamblers from both drop-out groups had played for longer than five years and were playing daily or more often [20]. How this contributes to drop-out seems apparent in that there could arguably be a more entrenched pattern of play resulting in a greater intractability of problem. This could be explained in a lack of desire to stop. It is possible that given the rationale of therapy the prospect of quitting is too difficult to imagine [13]. This may be due to worries and concerns over what the absence of play may mean to their lives [52]. It is not uncommon for people experiencing long-term or chronic conditions to be unprepared to alter behaviour which has become a part of their lives. This has been found in other conditions especially substance misuse [53]. This group may benefit from altering treatment so that the issues around no longer gambling come to the fore rather than starting with exposure. By doing this, they might be better prepared to eventually deal with the arousal experienced when confronted with gambling triggers. It may even be necessary to focus on a pure cognitive model where avoidance of such triggers is encouraged as with other programs [54,55]. However this may be helpful in the short term but could lead to problems with long term outcomes. The ability to avoid all gambling triggers especially connected to EGMs in Australia is highly unlikely. Australia has the highest proportion per capita of gambling machines in the world [56]. Therefore, allowing space for a gambler to come to terms with what is probably viewed as a major loss (i.e., no longer gambling) will ensure a greater response to exposure later.

\section{Limitations and future research}

This was a clinical outcome study and as such a number of limitations associated with such research are evident. Due to the small number of subjects in the drop-out from treatment specific comparisons could not be made between this group and those who only received one assessment session. The combining of both non-completer groups may therefore be misleading as they could easily be significantly different from one another. While all therapists were trained in the same approach to therapy, no record was made as to whether certain outcomes could be related to specific therapist's therapeutic approach. Such differences may have determined if an individual decided to proceed into therapy rather than failing to return after the initial assessment. Similarly, therapist matching did not occur and so some subjects may have been more prepared to engage in therapy had choices been available including same gender therapist. These issues could be addressed in future research.

\section{Conclusion}

This paper provides useful insights into the potential differences between completers and non-completers receiving CBT in an outpatient gambling treatment service. It is clear from this naturalistic study that a number of socio-demographics factors influence treatment outcomes and as such therapists need to pay attention to the impact this has on the therapeutic process. Similarly, certain gambling behaviours such as high spend and frequency of play is related to greater noncompletion rates. Once again the therapists should account for this when establishing the order of treatment techniques. This group may benefit from reversing the exposure and cognitive restructuring components. Finally, levels of co-morbidity have an effect on treatment completion, with non-completers showing higher anxiety, depression and functioning disability. Again, providing specific therapeutic input that addresses this may help improve successful outcomes. Overall, this paper shows that, in a natural clinic setting, CBT using a standardised model appears to have positive outcomes on problem gamblers. 
Citation: Tolchard B, Battersby M (2013) Treatment Completion in a Cognitive Behaviour Therapy Service for Problem Gamblers: Clinical Outcome Study. J Addict Res Ther 4: 165. doi: 10.4172/2155-6105.1000165

\section{References}

1. Schwartz DG (2006) The history of gambling: Roll the bones, New York, Gotham Books.

2. American Psychiatric Association (1994) Diagnostic and statistical manual of mental disorder: Washington DC

3. World Health Organisation (1992) International classification of diseases-10: Geneva, WHO.

4. Achab S, Khazaal Y (2011) Psychopharmacological treatment in pathological gambling: a critical review. Curr Pharm Des 17: 1389-1395.

5. Marceaux JC, Melville CL (2011) Twelve-step facilitated versus mappingenhanced cognitive-behavioral therapy for pathological gambling: A controlled study. J Gambl Stud 27: 171-190.

6. Pallesen S, Mitsem M, Kvale G, Johnsen BH, Molde H (2005) Outcome of psychological treatments of pathological gambling: A review and meta-analysis. Addiction 100: 1412-1422.

7. Battersby M, Oakes J, Tolchard B, Forbes A, Pols R (2008) Cognitive behavioral therapy for problem gamblers. In the Pursuit of Winning 179-197.

8. Echeburúa E, Báez C, Fernández-Montalvo J (1996) Comparative effectiveness of three therapeutic modalities in the psychological treatment of pathological gambling: Long-term outcome. Behavioural and Cognitive Psychotherapy 24: $51-72$

9. Ladouceur R, Lachance S (2007) Overcoming pathological gambling: therapist guide: Oxford University Press New York.

10. Tolchard B (2009) Early identification and the risk factors associated with problem gambling: implications for clinical practice, The University of Essex.

11. Tolchard B, Battersby M (2001) Nurse behavioural psychotherapy and pathological gambling: An Australian perspective. J Psychiatr Ment Health Nurs 7: $335-342$.

12. Tolchard B, Battersby M (2013) Cognitive Behaviour Therapy for Problem Gamblers: A Clinical Outcomes Evaluation. Behaviour Change 30: 12-23.

13. Melville KM, Casey LM, Kavanagh DJ (2007) Psychological treatment dropout among pathological gamblers. Clin Psychol Rev 27: 944-958.

14. Ladouceur R, Sylvain C, Boutin C, Lachance S, Doucet C, et al. (2003) Group therapy for pathological gamblers: A cognitive approach. Behav Res Ther 41: 587-596.

15. Robson E, Edwards J, Smith G, Colman I (2002) Gambling decisions: An early intervention program for problem gamblers. J Gambl Stud 18: 235-255.

16. Petry NM, Weiss $L$ (2009) Social support is associated with gambling treatment outcomes in pathological gamblers. Am J Addict 18: 402-408.

17. Ingle PJ, Marotta J, McMillan G, Wisdom JP (2008) Significant others and gambling treatment outcomes. J Gambl Stud 24: 381-392.

18. Brown RIF (1986) Dropouts and continuers in Gamblers Anonymous: Lifecontext and other factors. Journal of Gambling Behavior 2: 130-140.

19. Guo S, Manning V, Thane KKW, Ng A, Abdin E, et al. (2012) Predictors of Treatment Outcome Among Asian Pathological Gamblers (PGs): Clinical, Behavioural, Demographic, and Treatment Process Factors. J Gambl Stud (in press).

20. Dowling $N$ (2009) Client characteristics associated with treatment attrition and outcome in female pathological gambling. Addiction Research \& Theory 17 205-219.

21. Leblond J, Ladouceur R, Blaszczynski A (2003) Which pathological gamblers will complete treatment? Br J Clin Psychol 42: 205-209.

22. Grant JE, Kim W, Kuskowski M (2004) Retrospective review of treatmen retention in pathological gambling. Compr Psychiatry 45: 83-87.

23. Smith D, Harvey P, Battersby M, Pols R, Oakes J, et al. (2010) Treatment outcomes and predictors of drop out for problem gamblers in South Australia: A cohort study. Aust N Z J Psychiatry 44: 911-920.

24. Dunn K, Delfabbro P, Harvey P (2012) A preliminary, qualitative exploration of the influences associated with drop-out from cognitive-behavioural therapy for problem gambling: An Australian perspective. J Gambl Stud 28: 253-272.

25. Dowling N, Cosic S (2011) Client engagement characteristics associated with problem gambling treatment outcomes. Int J Ment Health Addict 9: 656-671.
26. Jimenez-Murcia S, Aymamí N, Gómez-Peña M, Santamaría JJ, Álvarez-Moya E, et al. (2012) Does exposure and response prevention improve the results of group cognitive-behavioural therapy for male slot machine pathological gamblers? Br J Clin Psychol 51: 54-71.

27. Ben-Tovim D, Esterman A, Tolchard B, Battersby M (2001) The Victorian gambling screen. Gambling Research Panel, Melbourne.

28. Tolchard B, Battersby M (2010) The Victorian Gambling screen: reliability and validation in a clinical population. J Gambl Stud 26: 623-638.

29. Tolchard B, Delfabbro P (2013) The Victorian Gambling Screen: Validity and Reliability in an Adolescent Population. Int J Ment Health Addict 514-525.

30. Delfabbro P, Lahn J, Grabosky P (2006) Psychosocial correlates of problem gambling in Australian students. Aust N Z J Psychiatry 40: 587-595.

31. Mcmillen J, Wenzel M (2006) Measuring problem gambling: Assessment of three prevalence screens. International Gambling Studies 6: 147-174.

32. Battersby M, Thomas L, Tolchard B, Esterman A (2002) The South Oaks Gambling screen: a review with reference to Australian use. J Gambl Stud 18: 257-271.

33. Lesieur HR, Blume SB (1987) The South Oaks Gambling Screen (SOGS): A new instrument for the identification of pathological gamblers. Am J Psychiatry 144: 1184-1188.

34. Slutske WS, Zhu G, Meier MH, Martin NG (2011) Disordered gambling as defined by the DSM-IV and the South Oaks Gambling Screen: Evidence for a common etiologic structure. J Abnorm psychol 120: 743.

35. Beck AT, Ward CH, Mendelson M, Mock J, Erbaugh J (1961) An inventory for measuring depression. Arch Gen Psychiatry 4: 561-571.

36. Beck AT, Epstein N, Brown G, Steer RA (1988) An inventory for measuring clinical anxiety: psychometric properties. J Consult Clinical Psychol 56: 893897.

37. Marks IM, Hallam R, Connolly J, Philpott R (1977) Nursing in behavioural psychotherapy: An Advanced Clinical Role for Nurses: Royal College of Nursing of the United Kingdom.

38. Clark DM (2011) Implementing NICE guidelines for the psychological treatment of depression and anxiety disorders: the IAPT experience. Int Rev Psychiatry 23: 318-327.

39. Marks I (2009) Mental health clinics in the 21st century. Psychother Psychosom 78: $133-138$

40. Mundt JC, Marks IM, Shear MK, Greist JH (2002) The Work and Socia Adjustment Scale: a simple measure of impairment in functioning. $\mathrm{Br} J$ Psychiatry 180: 461-464.

41. Cella M, Sharpe M, Chalder T (2011) Measuring disability in patients with chronic fatigue syndrome: reliability and validity of the Work and Social Adjustment Scale. J Psychosom Res 71: 124-128.

42. Tchanturia K, Hambrook D, Curtis H, Jones T, Lounes N, et al. (2013) Work and social adjustment in patients with anorexia nervosa. Compr Psychiatry 54 $41-45$

43. Stanford E (1998) Evaluation of the gamblers rehabilitation fund final report Adelaide Department of Human Services.

44. Tolchard B, Battersby M (2000) Evaluation of the intensive therapy services fo problem gamblers an in-patient program. Australas Psychiatry 34: A67-A67.

45. Australian Bureau of Statistics (2006) Year book Australia 2002. Health special article-suicide.

46. S.A. Department for Families and Communities (2006) Gambling prevalence in South Australia: October to December 2005. Adelaide: DFC.

47. Gainsbury S, Blaszczynski A (2011) A systematic review of Internet-based therapy for the treatment of addictions. Clin Psychol Rev 31: 490-498.

48. Monaghan S, Blaszczynski A, Nower L (2009) Consequences of winning: the role of gambling outcomes in the development of irrational beliefs. Behav Cogn Psychother 37: 49-59.

49. Raylu N, Oei TP (2007) Factors that predict treatment outcomes in a community treatment agency for problem gamblers. Int J Ment Health Addict 5: 165-176.

50. Smith SA, Thomas SA, Jackson AC (2004) An exploration of the therapeutic relationship and counselling outcomes in a problem gambling counselling service. Journal of Social Work Practice 18: 99-112. 
Citation: Tolchard B, Battersby M (2013) Treatment Completion in a Cognitive Behaviour Therapy Service for Problem Gamblers: Clinical Outcome Study. J Addict Res Ther 4: 165. doi: 10.4172/2155-6105.1000165

51. Marks IM, Gega L (2009) Review by Jeroen Ruwaard and Alfred Lange (Cognitive Behaviour Therapy, 2009, 38(2), p. 132) of Hands-on-Help: Computer-Aided Psychotherapy (Maudsley Monograph 49) by I. M. Marks, K. Cavanagh, and L. Gega. New York: Psychology Press 2007. Letter to the editors. Cogn Behav Ther 38: 192

52. Lipinski D, Whelan JP, Meyers AW (2007) Treatment of pathological gambling using a guided self-change approach. Clinical Case Studies 6: 394-411.

53. Mueser KT, Noordsy DL, Drake RE, Fox L (2003) Integrated Treatment for Dual Disorders: A Guide to Effective Practice. London: The Guilford Press.
54. Ladouceur R, Sylvain C, Boutin C, Lachance S, Doucet C, et al. (2001) Cognitive treatment of pathological gambling. J Nerv Ment Dis 189: 774780.

55. Petry NM, Ammerman Y, Bohl J, Doersch A, Gay H, et al. (2006) Cognitivebehavioral therapy for pathological gamblers. J Consult Clin Psychol 74: 555567.

56. Pickernell DG, Keast RL, Brown KA (2010) Social clubs and social capital: The effect of electronic gaming machines in disadvantaged regions on the creation or destruction of community resilience.
Citation: Tolchard B, Battersby M (2013) Treatment Completion in a Cognitive Behaviour Therapy Service for Problem Gamblers: Clinical Outcome Study. J Addict Res Ther 4: 165. doi: 10.4172/2155-6105.1000165
Submit your next manuscript and get advantages of OMICS Group submissions

\footnotetext{
Unique features:
}

User friendly/feasible website-translation of your paper to 50 world's leading languages Audio Version of published paper

- Digital articles to share and explore

Special features:

300 Open Access Journals

25,000 editorial team

21 days rapid review process

Quality and quick editorial, review and publication processing

Indexing at PubMed (partial), Scopus, EBSCO, Index Copernicus and Google Scholar et

- Sharing Option: Social Networking Enabled

Authors, Reviewers and Editors rewarded with online Scientific Credits

Better discount for your subsequent articles

Submit your manuscript at: http://www.omicsonline.org/submission 